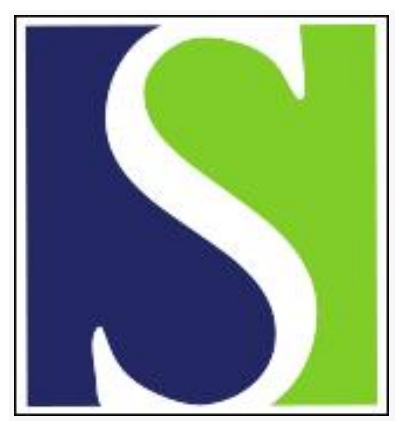

Scand J Work Environ Health 2006;32(2):121-131

https://doi.org/10.5271/sjweh.987

Issue date: 30 Apr 2006

\title{
Disturbed sleep and fatigue in occupational burnout
}

by Ekstedt M, Söderström M, Åkerstedt T, Nilsson J, Søndergaard H-P, Aleksander $P$

Affiliation: National Institute of Psychosocial Factors and Health, Box 230, SE-17177 Stockholm, Sweden. mirjam.ekstedt@ipm.ki.se

Refers to the following text of the Journal: 1999;25(6):605-609

The following articles refer to this text: 2006;32(6):493-501;

2008;34(1):23-32; 2014;40(6):569-581; 2017;43(4):337-349

Key terms: arousal; burnout; disturbed sleep; fatigue; mental fatigue; occupational burnout; polysomnography; sleep; sleepiness

This article in PubMed: www.ncbi.nlm.nih.gov/pubmed/16680382 


\title{
Disturbed sleep and fatigue in occupational burnout
}

\author{
by Mirjam Ekstedt, PhD, ${ }^{1}$ Marie Söderström, MSc, ${ }^{1}$ Torbjörn Åkerstedt, PhD, ${ }^{1,2}$ Jens Nilsson, BA, ${ }^{1}$ Hans- \\ Peter Søndergaard, PhD, ${ }^{1}$ Perski Aleksander, PhD ${ }^{1}$
}

\begin{abstract}
Ekstedt M, Söderström M, Åkerstedt T, Nilsson J, Søndergaard H-P, Aleksander P. Disturbed sleep and fatigue in occupational burnout. Scand J Work Environ Health 2006;32(2):121-131.
\end{abstract}

\begin{abstract}
Objectives The purpose of this study was to investigate sleep with polysomnography and self-ratings and the diurnal pattern of sleepiness and fatigue in a group suffering from severe occupational burnout.

Method Twelve white-collar workers on long-term sick leave ( $>3$ months) and 12 healthy controls with high and low scores on the Shirom Melamed Burnout Questionnaire (SMBQ) were included. A 1-night polysomnographic recording (after habituation) was carried out at home, and sleepiness and mental fatigue were rated at different times of the day for weekdays and the weekend. Precipitating factors at the time of the illness at work and real life were considered, and different dimensions of occupational fatigue were described. A repeatedmeasures analysis of variance using two or three within group factors was used to analyze the data.

Results The main polysomnographic findings were more arousals and sleep fragmentation, more wake time and stage-1 sleep, lower sleep efficiency, less slow wave sleep and rapid eye movement sleep, and a lower delta power density in nonrapid eye movement sleep in the burnout group. The burnout patients showed pronounced sleepiness and mental fatigue at most times of the day for weekdays without reduction during weekends. The precipitating factor was occupational stress (psychiatric interview), and work stress indicators were increased. Conclusions Occupational burnout is characterized by impaired sleep. It is suggested that impaired sleep may play a role in the development of fatigue or exhaustion in burnout.
\end{abstract}

Key terms arousal; burnout; mental fatigue; polysomnography; sleep; sleepiness.

During the last 10 years there has been considerable interest in the problem of "burnout" in western countries, particularly in Sweden, because of its significance for the large increase in long-term sickness absence during this period $(1,2)$. The concept of burnout describes a state of "chronic depletion of an individual's energetic resources" (3), resulting from prolonged occupational stress $(4,5)$. Originally, the symptoms were found to occur only in client-related occupations (5), but now include all types of work $(6,7)$.

The characteristic symptoms of burnout are excessive and persistent fatigue, emotional exhaustion, and cognitive dysfunction $(8,9)$. Frequently, the condition also includes components of depersonalization or cynicism against work or clients and reduced personal efficacy, with a tendency to evaluate oneself negatively (5). Burnout is not a formally accepted diagnostic category in the international diagnostic classification systems and the diagnostic label commonly used in the ICD-10 (the 10th revision of the International Classification of Dis- eases (10) is Z73.0, in which burnout is broadly defined as "a state of vital exhaustion". Recently "exhaustion syndrome" has been established as an ICD diagnosis in the Swedish version (KSH97, \#F43.8A) (11).

The fatigue component dominates in burnout and overlaps with disorders such as chronic fatigue syndrome (12), vital exhaustion (13), and depression (14, 15). In these states, as in burnout, there is a tendency to treat fatigue in a generic way although the concept seems to have several dimensions, such as affective, muscular, cognitive, and physical fatigue $(16,17)$. In addition the etiology is different.

The physiological mechanism behind fatigue in burnout has not been identified, but the role of long-term stress suggests that the hypothalamo-pituitary-adrenal (HPA) axis is involved $(18,19)$. An alternative or complementary factor could be disturbed sleep. It has recently been demonstrated that burnout scores are closely related to reports of disturbed sleep $(20,21)$, and disturbed and shortened sleep is closely related to sleepiness

1 National Institute of Psychosocial Factors and Health, Stockholm, Sweden.

2 Department of Public Health Science, Karolinska Institutet, Stockholm, Sweden.

Reprint requests to: Dr M Ekstedt, National Institute of Psychosocial Factors and Health, Box 230, SE-17177 Stockholm, Sweden. [E-mail: mirjam.ekstedt@ipm.ki.se] 
and fatigue $(22,23)$. No studies of physiological sleep in relation to burnout have been carried out, however, except for our recent investigation of young persons with high burnout scores working in a company involved in information technology (24). The main finding was an increased level of sleep fragmentation, and an interesting question is whether sleep impairment is greater in more severe cases.

Furthermore, considering the lack of recuperation after sleep or rest, which is part of the definition of the syndrome, it is remarkable that the experience of fatigue has never been described in terms of pattern across the week or across the day, except for the previously mentioned study by Söderström et al (24). This study showed a lack of the normal increase in alertness during the weekend, and this deviating pattern of sleepiness may well be a characteristic also of chronic burnout. Incidentally, the reason for studying both fatigue and sleepiness is that, although correlated, the latter represents a drive to fall asleep, whereas fatigue is more of a disinclination towards activity (25). Furthermore, the acute daily and weekly pattern of subjective mental fatigue has never been studied in burnout.

The aim of the current study was to extend the previous work on sleep, sleepiness, and fatigue to a group with a more severe level of burnout that might be diagnosed in company health care facilities. For this purpose, we selected people on long-term sick leave $(>90$ days) because of occupational burnout, but lacking a formal diagnosis; the Shirom Melamed Burnout Questionnaire (SMBQ) was used for screening. To describe sleep as realistically as possible, polysomnographic sleep recordings were made in the home environment. The weekend was included for the subjective ratings. An average day in the workweek was selected for the sleep recordings.

\section{Study population and methods}

\section{Participants}

Twenty-four persons participated in the study-12 burnout patients and 12 matched healthy controls. Three of the burnout patients and three of the controls were wom- en, and men comprised the remainder of both groups. The mean age of the burnout and control groups was 40 (SD 2) years and 39 (SD 2) years, respectively. Information on other sociodemographic variables is presented in table 1.

The burnout group was recruited from the registers of an insurance company serving white-collar workers. Fifty-eight volunteers were examined and included if (i) they had a high burnout score ( $>4.5$, on a scale of $1-7)$ on the SMBQ (8), based on clinical data from the stress clinic at the Karolinska Institutet (26), (ii) they were on sick leave (full-time) for at least 3 months, and (iii) their complaints were related to work. Lacking a formal ICD diagnosis, the Z73.0 (10) was used as important additional inclusion criteria.

In order to assess psychiatric comorbidity, a clinical psychiatrist assessed the participants using the Structured Clinical Interview for DSM-IV (SCID) (27). Before the interview, the participants completed questionnaires to assess previous life events (28) and the screening questionnaire for personality disorders (SCID-scan) (29). The SCID (including the SCID-scan) was done to exclude Axis II diagnoses as defined by the Diagnostic and Statistical Manual of the American Psychiatric Association, 4th Edition (DSM-IV) (14). Sixty-five percent of the patients had a diagnosis of depression at the beginning of the illness episode, but people with ongoing major depression and other primary Axis I disorders were excluded from the study. No patients fulfilled criteria for an Axis II disorder.

The burnout group and controls were medically examined before the study, and participants with infections or a medical history of chronic fatigue syndrome, fibromyalgia, autoimmune diseases, Cushing's syndrome, or other chronic diseases that might possibly explain fatigue were excluded from the study. Other exclusion criteria were heavy snoring, sleep apnea (as evidenced in self-reports and oxygen desaturation measurements), and the use of antidepressant medication, hypnotics, beta-receptor blockers, and other medication known to interfere with sleep. On the basis of the psychiatric evaluation, work-related problems were the precipitating factor in all of the cases; 64\% also reported family stress.

Table 1. Characteristics of the burnout group $(\mathrm{N}=12)$ and healthy controls $(\mathrm{N}=12)$. ( $\mathrm{SE}=$ standard error of the mean)

\begin{tabular}{|c|c|c|c|c|c|c|c|c|c|c|c|c|c|c|c|c|c|c|c|c|}
\hline \multirow[t]{3}{*}{ Group } & \multicolumn{3}{|c|}{$\begin{array}{l}\text { Body mass } \\
\text { index }\left(\mathrm{kg} / \mathrm{m}^{2}\right)\end{array}$} & \multicolumn{3}{|c|}{$\begin{array}{l}\text { Waist-to-hip } \\
\text { ratio }\end{array}$} & \multirow{2}{*}{\multicolumn{2}{|c|}{$\begin{array}{c}\text { Married } \\
\text { or } \\
\text { cohabiting }\end{array}$}} & \multirow{2}{*}{\multicolumn{2}{|c|}{$\begin{array}{l}\text { Education } \\
\text { (uni- } \\
\text { versity) }\end{array}$}} & \multirow{2}{*}{\multicolumn{2}{|c|}{$\begin{array}{c}\text { Children } \\
(<12 \\
\text { years })\end{array}$}} & \multirow{2}{*}{\multicolumn{2}{|c|}{$\begin{array}{c}\text { Sick leave } \\
(>90 \\
\text { days) }\end{array}$}} & \multirow{2}{*}{\multicolumn{2}{|c|}{$\begin{array}{l}\text { Seden- } \\
\text { tary } \\
\text { lifestyle }\end{array}$}} & \multirow{2}{*}{\multicolumn{2}{|c|}{$\begin{array}{l}\text { Current } \\
\text { smoker }\end{array}$}} & \multirow{2}{*}{\multicolumn{2}{|c|}{$\begin{array}{l}\text { Alcohol in- } \\
\text { take ( } \geq \text { once } \\
\text { /week) }\end{array}$}} \\
\hline & Men & \multicolumn{2}{|c|}{ Women } & \multirow{2}{*}{$\frac{\text { Men }}{\text { Mean SE }}$} & \multicolumn{2}{|c|}{ Women } & & & & & & & & & & & & & & \\
\hline & Mean SE & Mean & SE & & Mean & SE & $N$ & $\%$ & $N$ & $\%$ & $N$ & $\%$ & $N$ & $\%$ & $N$ & $\%$ & $\mathrm{~N}$ & $\%$ & $N$ & $\%$ \\
\hline Burnout & 23.02 & 22.6 & 1 & 0.90 .1 & 0.8 & 0.0 & 8 & 67 & 6 & 50 & 4 & 33 & 12 & 100 & 8 & 30 & 6 & 22 & 5 & 42 \\
\hline Control & $25.3 \quad 2$ & 22.7 & 0.4 & $\begin{array}{ll}0.9 & 0.0\end{array}$ & 0.8 & 0.0 & 10 & 83 & 7 & 58 & 3 & 33 & 0 & 0 & 4 & 25 & 6 & 37 & 3 & 33 \\
\hline
\end{tabular}


Healthy controls were contacted through internal advertisement at the insurance company or through personal contacts. Out of 45 volunteers, 12 controls of fulltime white-collar workers (similar to the patients with respect to gender, age, and occupation) were recruited. These met the aforementioned inclusion criteria except that they needed to have a low score on the SMBQ scale $(\leq 2.75)$. After recruitment, the participants were given verbal information about the procedures, and they all signed a consent form. There was no monetary incentive involved for the patient group (which was on sick leave), but the control group received an economic compensation of EUR $\approx 220$. The study was approved by the ethics committee of the Karolinska Institutet.

\section{Procedure}

During a 10-day period with diary ratings of the sleepwake pattern, sleepiness, and fatigue, all of the participants were subjected to a polysomnographic recording in their home (after one night of habituation the preceding week). Bedtime and the time of rising were at the discretion of the participants and in accordance with their habitual pattern. At the beginning of the recording period, a questionnaire on the current sleep pattern, work characteristics, health status, medication, and intellectual functioning was completed. In addition, some questionnaires were filled out.

\section{Polysomnography}

Sleep was recorded polysomnographically using "Embla" recorders (Flaga HF${ }^{\circledR}$, Medcare, Reykjavik, Iceland) with two electroencephalographic (EEG) derivations $\mathrm{C} 3-\mathrm{A} 2$ and $\mathrm{C} 4-\mathrm{A} 1$, one chin electromyographic (EMG) derivation and two electro-oculogram derivations (EOG) (oblique derivations). Silver/silver chloride electrodes were used. Sleep stages were scored visually in 30-second epochs according to Rechtschaffen \& Kales (30). The sleep scoring was blind to group membership. Arousals were scored using the criteria of the American Sleep Disorders Association (31). An arousal was defined as an EEG shift to at least alpha activity from stages $2-4$ or rapid eye movement (REM) sleep, preceded by at least 10 seconds of uninterrupted sleep (stages 2-4 or REM). During REM sleep an increase in EMG activity was required. For an arousal to be scored, it had to last for more than 3 seconds and for less than 15 seconds. Sleep onset latency was scored as time from "eyes closed" to the first epoch of at least three consecutive sleep epochs (stage 1 or other sleep stages).

Spectral analysis, fast fourier transform (FFT) of the EEG, was also carried out. The EEG was sampled at a frequency of $100 \mathrm{~Hz}$ using conventional filter settings (band pass filter set to $0.5-32 \mathrm{~Hz}$ ). The FFT analysis was based on 4-second epochs, and after visual artifact detection the entire 4-second "subepoch" was removed from the analysis and substituted by the mean of the immediately adjacent epochs. Values were then integrated across each band and averaged across 1-minute intervals of sleep. The bands used were $0.5-4.5 \mathrm{~Hz}$ (delta), 4.51-7.5 Hz (theta), 7.51-12.5 Hz (alpha), 12.5116.50 (sigma), and $16.51-32.5 \mathrm{~Hz}$ (beta).

\section{Questionnaires}

Burnout was measured using the SMBQ $(8,9)$, which consists of 22 symptom sentences that form four dimensions of the burnout syndrome, emotional and physical exhaustion, tension, listlessness, and cognitive weariness. Each item was scored on a seven-point scale graded from 1 (almost never) to 7 (almost always). Chronbach's alpha for the index was 0.90 . The SMBQ correlates highly with the emotional exhaustion subscale of the Maslachs Burnout Inventory) (6) and with the Pines Burnout Measure (32). The Beck Depression Inventory (BDI) (33) and the Beck Anxiety Inventory (BAI) (34) were used to assess depression and anxiety. Single items measured the habitual pattern of recovery: "I have enough time available for rest and recovery" and "I am able to relax when I need to". The response alternatives varied from 1 "I totally agree" to 5 "I totally disagree".

Habitual sleep quality was assessed with the Karolinska Sleep Questionnaire (35). From it the sleep quality index (SQI) was determined; it includes the initiation and maintenance of sleep, with the items "sleep quality", "calmness of sleep", "ease of falling asleep", and "sleep throughout the allotted time". The response alternatives were $6=$ always or almost every day, $5=$ very often or $\geq 4$ days per week, $4=$ mostly or several days per week, $3=$ sometimes or several times per month, $2=$ seldom or a few times per year, and $1=$ never. A sleep sufficiency index (SSI = sleep time or habitual sleep need $\times 100$ ) was calculated from the habitual sleep need. Habitual frequency and the length of naps were registered as well.

Work characteristics were assessed in the questionnaire and consisted of psychosocial work factors, inspired by the demand-control-support model (36) and effort-reward model (37). Items on the time pressure and work interference with leisure or relaxation (38) were also assessed. The following two indices were formed: "demands at work" with the items "high workpace", "work never ends", "it always requires top performance", and "high skill demands" (Chronbach's $\alpha=0.85$ ) and "decision latitude" with the terms "possibility to delegate when I'm overloaded", "take part in decisions", and "free to chose how to do my work" (Chronbach's $\alpha=0.76$ ). The response alternatives were 1 (not at all or low) to 4 (to a great extent or high). 


\section{Diary ratings}

Subjective sleep characteristics were reported upon awakening each morning using the Karolinska Sleep diary $(\mathrm{KSD})(39,40)$. It contained 10 items (response alternatives graded from 6 to 1), reflecting problems of initiating and maintaining sleep, as well as a global appreciation of sleep. The following four items formed a SQI: "sleep quality", "calm sleep", "ease of falling asleep", and "ability to sleep throughout the allotted time". The diary has been validated against polysomnography and showed good correlations with objective sleep parameters (41). The frequency and length of napping was registered in the diary on the day of the EEG.

The daytime ratings included sleepiness and mental fatigue and were carried out at awakening (around 0700) and approximately at 1000, 1400, 2000, and bedtime. Sleepiness was rated on the Karolinska Sleepiness Scale (KSS) ranging from 1 to 9 (very alert-extremely sleepy, fighting sleep, an effort to remain awake). It has been validated against electrophysiological indices of sleepiness (42). Mental fatigue was rated on a 9-point scale ranging from $1=$ very fresh to $9=$ totally exhausted. The daytime diary also included questions on mood and how the day had been concerning levels of energy and physical activity. The response alternatives varied from 1 "very low" or "distressed" to 9 "very high" or "happy". Three items on aching joints, headache, and muscle tension formed an ache-tension index. The response scale varied from 1 "not at all" to 5 "to a high degree".

\section{Statistical analysis}

The group comparisons between burnout patients and healthy controls were carried out using unpaired t-tests or chi-square tests as appropriate. All of the values in the analyses are expressed as the mean and the standard error of the mean. For the development of sleepiness and mental fatigue across days a repeated-measures analysis of variance (ANOVA) using two or three within-group factors, groups (burnout patients and healthy controls), time of day (awakening to bedtime) and days (weekday and weekends) was applied. This procedure included correction for sphericity using the Huyhn-Feldt procedure (43). However, for clarity, the unadjusted degrees of freedom are given. When appropriate, and after a significant main effect, pairwise t-tests were carried out to investigate the simple effects. All

Table 2. Means, standard errors of the means, and the t-test results of the sleep of the burnout patients and controls as measured by polysom

\begin{tabular}{|c|c|c|c|c|c|c|c|c|c|c|c|c|c|c|c|c|}
\hline \multirow[t]{2}{*}{ Group } & \multicolumn{2}{|c|}{ Bedtime } & \multicolumn{2}{|c|}{ Rise time } & \multicolumn{2}{|c|}{$\begin{array}{l}\text { Total sleep time } \\
\text { (min) }\end{array}$} & \multicolumn{2}{|c|}{$\begin{array}{l}\text { Sleep onset } \\
\text { latency } \\
\text { (min) }\end{array}$} & \multicolumn{2}{|c|}{$\begin{array}{l}\text { Sleep } \\
\text { efficiency } \\
(\%)\end{array}$} & \multicolumn{2}{|c|}{$\begin{array}{l}\text { Awakenings } \\
\text { stage } 0 \\
\text { (N) }\end{array}$} & \multicolumn{2}{|c|}{$\begin{array}{l}\text { Arousals/hour } \\
\text { (N) }\end{array}$} & \multicolumn{2}{|c|}{$\begin{array}{l}\text { Fragmentation } \\
\text { index/hour } \\
(\mathrm{N})\end{array}$} \\
\hline & Mean & SE & Mean & SE & Mean & SE & Mean & SE & Mean & $\mathrm{SE}$ & Mean & SE & Mean & SE & Mean & SE \\
\hline Burnout $(\mathrm{N}=12)$ & 2310 & 0010 & 0653 & 0010 & 373 & 23 & 21 & 6 & 85 & 0.02 & 16 & 1 & 20 & 3 & 25 & 3 \\
\hline Control $(\mathrm{N}=12)$ & 2305 & 0018 & 0642 & 0013 & 408 & 12 & 10 & 2 & 91 & 0.17 & 13 & 0.9 & 12 & 1 & 16 & 1 \\
\hline t-values & \multicolumn{2}{|c|}{0.2} & \multicolumn{2}{|c|}{0.6} & \multicolumn{2}{|c|}{-1.3} & \multicolumn{2}{|c|}{1.6} & \multicolumn{2}{|c|}{-4.1} & \multicolumn{2}{|c|}{1.3} & \multicolumn{2}{|c|}{2.6} & \multicolumn{2}{|c|}{2.7} \\
\hline P-values & \multicolumn{2}{|c|}{0.879} & \multicolumn{2}{|c|}{0.564} & \multicolumn{2}{|c|}{0.206} & \multicolumn{2}{|c|}{0.131} & \multicolumn{2}{|c|}{0.000} & \multicolumn{2}{|c|}{0.204} & \multicolumn{2}{|c|}{0.014} & \multicolumn{2}{|c|}{0.014} \\
\hline
\end{tabular}

a Degrees of freedom 22.

${ }^{\mathrm{b}}$ Relative delta power $=$ delta $(0.5-4.5 \mathrm{~Hz}) /$ total power $(0.5-32.5 \mathrm{~Hz})$

Table 3. Diary ratings of the burnout patients and healthy controls for the weekday and weekend. $(\mathrm{SE}=$ standard error of the mean,

\begin{tabular}{|c|c|c|c|c|c|c|c|c|c|c|c|c|}
\hline \multirow[t]{3}{*}{ Group } & \multicolumn{12}{|c|}{ Sleep diary polysomnography recorded night } \\
\hline & \multicolumn{2}{|c|}{ Bed time } & \multicolumn{2}{|c|}{ Rise time } & \multicolumn{2}{|c|}{$\begin{array}{l}\text { Napping } \\
\text { (min) }\end{array}$} & \multicolumn{2}{|c|}{$\begin{array}{c}\text { Total sleep time - } \\
\text { WASO } \\
\text { (hours:min) }\end{array}$} & \multicolumn{2}{|c|}{$\begin{array}{l}\text { Sleep sufficiency } \\
\text { index } \\
(\%)\end{array}$} & \multicolumn{2}{|c|}{$\begin{array}{l}\text { Awakenings } \\
\text { (N) }\end{array}$} \\
\hline & Mean & SE & Mean & SE & Mean & SE & Mean & SE & Mean & SE & Mean & SE \\
\hline \multicolumn{13}{|c|}{ Burnout $(\mathrm{N}=12)$} \\
\hline Weekdays & 2306 & 0015 & 0708 & 0010 & 33 & 11 & $6: 27$ & 23 & 77 & 6 & 3.2 & 0.5 \\
\hline Weekend & 2348 & 0024 & 0819 & 0017 & - & $\cdot$ & $0: 38$ & $7: 01$ & 86 & 5 & 3.4 & 0.7 \\
\hline \multicolumn{13}{|c|}{ Control group ( $\mathrm{N}=12)$} \\
\hline Weekdays & 2312 & 0010 & 0627 & 0011 & 4 & 0.4 & $7: 10$ & $0: 13$ & 93 & 5 & 1.2 & 0.2 \\
\hline Weekend & 2334 & 0012 & 0759 & 0015 & - & $\cdot$ & $7: 49$ & $0: 20$ & 106 & 5 & 1.0 & 0.2 \\
\hline \multicolumn{13}{|l|}{ P-value a } \\
\hline Group & \multicolumn{2}{|c|}{0.944} & \multicolumn{2}{|c|}{0.230} & \multicolumn{2}{|c|}{$\cdot$} & \multicolumn{2}{|c|}{0.263} & \multicolumn{2}{|c|}{0.013} & \multicolumn{2}{|c|}{0.013} \\
\hline Day & \multirow{2}{*}{\multicolumn{2}{|c|}{$\begin{array}{l}0.008 \\
0.334\end{array}$}} & \multirow{2}{*}{\multicolumn{2}{|c|}{$\begin{array}{l}0.000 \\
0.410\end{array}$}} & \multicolumn{2}{|c|}{0.010} & \multirow{2}{*}{\multicolumn{2}{|c|}{$\begin{array}{l}0.007 \\
0.695\end{array}$}} & \multicolumn{2}{|c|}{0.005} & \multicolumn{2}{|c|}{0.961} \\
\hline Interaction & & & & & & & & & & & & \\
\hline
\end{tabular}

${ }^{a}$ Results from the analysis of variance, presented as the mean and SE, degrees of freedeom 1/21-22. 
of the calculations were carried out using Statview software (version 5.0.1, SAS Institute Inc, Cary, NC, USA) and SPSS 11.0 for Macintosh (SPSS Inc, Chicago, IL, USA). An alpha level of 0.05 was considered to be statistically significant.

\section{Results}

\section{Polysomnography}

Table 2 summarizes the polysomnographical results. The burnout group showed significantly worse values for sleep efficiency, frequency of arousals, fragmentation index (number of arousals + number of awakenings to stage 0 and stage 1 ), wake time after sleep onset and stage-1 sleep. It also showed less slow-wave sleep, less rapid eye movement sleep, and less slow-wave activity during nonrapid eye movement sleep. The analysis did not reveal any differences in power density in the nonrapid eye movement stage for the theta, alpha, beta, or sigma frequencies (not in table). In rapid eye movement sleep, no significant differences in power density were obtained for any of the calculated frequency bands. When naps, obtained from the diary, were controlled for, the differences between the groups remained. No significant correlations were found between the BDI and the sleep variables.

\section{Sleep and wake diary}

The diary ratings of sleep for the polysomnographically recorded night and weekend sleep are presented in table 3 . The burnout group showed significantly more awakenings, lower sleep quality, and less sufficient sleep. The bed and rise times did not differ. Most of the variables showed a clear weekend effect-later sleep hours, longer sleep, and more sufficient sleep. Sleep quality and the number of awakenings were not affected, however. No interactions were found. Forty-two percent $(\mathrm{N}=5)$ of the burnout patients usually took a nap during the day (according to questionnaire data: mean 42 (range 20-90) minutes), while only $8 \%(\mathrm{~N}=1)$ in the control group were napping regularly. There was no significant correlation between naptime during the EEG day and the frequency of arousals $(r=0.12)$, total sleep time $(r=-0.26)$, sleep latency $(r=-0.26)$, sleep efficiency

nography. [SWS = slow-wave sleep (stages 3+4), REM = rapid eye movement sleep, NREM = non-rapid eye movement sleep (stage 2+3+4)]

\begin{tabular}{|c|c|c|c|c|c|c|c|c|c|c|c|c|c|c|c|c|c|}
\hline \multicolumn{2}{|c|}{$\begin{array}{l}\text { Wake time } \\
\text { after sleep } \\
\text { onset (\%) }\end{array}$} & \multicolumn{2}{|c|}{$\begin{array}{c}\text { Stage } 1 \\
(\%)\end{array}$} & \multicolumn{2}{|c|}{$\begin{array}{c}\text { Stage } 2 \\
(\%)\end{array}$} & \multicolumn{2}{|c|}{$\begin{array}{l}\text { SWS } \\
\text { latency } \\
\text { (min) }\end{array}$} & \multicolumn{2}{|c|}{$\begin{array}{l}\text { Slow wave } \\
\text { activity } \\
(\%)\end{array}$} & \multicolumn{2}{|c|}{$\begin{array}{l}\text { REM sleep } \\
\text { latency } \\
\text { (min) }\end{array}$} & \multicolumn{2}{|c|}{$\begin{array}{l}\text { REM } \\
(\%)\end{array}$} & \multicolumn{2}{|c|}{$\begin{array}{c}\text { SWA NREM } \\
\left(\mu \mathrm{V}^{2}\right)\end{array}$} & \multicolumn{2}{|c|}{$\begin{array}{l}\text { Relative delta } \\
\text { power NREM }\end{array}$} \\
\hline Mean & SE & Mean & SE & Mean & SE & Mean & SE & Mean & SE & Mean & SE & Mean & SE & Mean & SE & Mean & SE \\
\hline 13.4 & 2 & 5.2 & $\approx 0.8$ & 43 & 3 & 18 & 3 & 10.0 & 1.1 & 78 & 10 & 19 & 2 & 225 & 17 & 0.77 & 0.2 \\
\hline 6.8 & 0.7 & 3.2 & 0.3 & 42 & 1 & 14 & 1 & 15.4 & 1.5 & 65 & 4 & 24 & 1 & 290 & 19 & 0.84 & 0.2 \\
\hline \multicolumn{2}{|c|}{3.0} & \multicolumn{2}{|c|}{2.2} & \multicolumn{2}{|c|}{0.1} & \multicolumn{2}{|c|}{1.1} & \multicolumn{2}{|c|}{-2.9} & \multicolumn{2}{|c|}{1.1} & \multicolumn{2}{|c|}{-2.5} & \multicolumn{2}{|c|}{-2.4} & \multicolumn{2}{|c|}{-2.2} \\
\hline \multicolumn{2}{|c|}{0.007} & \multicolumn{2}{|c|}{0.041} & \multicolumn{2}{|c|}{0.904} & \multicolumn{2}{|c|}{0.264} & \multicolumn{2}{|c|}{0.008} & \multicolumn{2}{|c|}{0.289} & \multicolumn{2}{|c|}{0.022} & \multicolumn{2}{|c|}{0.033} & \multicolumn{2}{|c|}{0.042} \\
\hline
\end{tabular}

KSS $=$ Karolinska sleepiness scale, WASO $=$ wake time after sleep onset, SSI = sleep time/habitual sleep need $\times 100$ )

\begin{tabular}{|c|c|c|c|c|c|c|c|c|c|c|c|}
\hline & & \multicolumn{10}{|c|}{ Daytime ratings EEG-day and weekend } \\
\hline \multicolumn{2}{|c|}{$\begin{array}{l}\text { Sleep quality } \\
\text { (1-5 very good) }\end{array}$} & \multicolumn{2}{|c|}{$\begin{array}{l}\text { Sufficient sleep } \\
\text { (1-5 definitely) }\end{array}$} & \multicolumn{2}{|c|}{$\begin{array}{l}\text { Ache or tension } \\
\text { (1 high degree- } \\
5 \text { not at all) }\end{array}$} & \multicolumn{2}{|c|}{$\begin{array}{c}\text { Mood } \\
(9 \text { very happy- } \\
1 \text { very distressed })\end{array}$} & \multicolumn{2}{|c|}{$\begin{array}{c}\text { Physical activity) } \\
\text { (1-9 very } \\
\text { high level) }\end{array}$} & \multicolumn{2}{|c|}{$\begin{array}{c}\text { Energy } \\
(1-9 \text { very } \\
\text { high level) }\end{array}$} \\
\hline Mean & SE & Mean & SE & Mean & SE & Mean & SE & Mean & SE & Mean & SE \\
\hline 3.5 & 0.2 & 2.6 & 0.2 & 3.3 & 0.3 & 5.2 & 0.4 & 4.5 & 0.5 & 4.0 & 0.4 \\
\hline 3.6 & 0.2 & 3.4 & 0.3 & 3.0 & 0.3 & 5.6 & 0.3 & 5.0 & 0.4 & 4.7 & 0.4 \\
\hline 4.4 & 0.01 & 3.7 & 0.2 & 1.3 & 0.1 & 7.3 & 0.3 & 6.7 & 0.2 & 7.0 & 0.2 \\
\hline 4.5 & 0.13 & 4.1 & 0.2 & 1.3 & 0.1 & 7.7 & 0.2 & 6.7 & 0.4 & 6.7 & 0.2 \\
\hline \multicolumn{2}{|c|}{0.000} & \multicolumn{2}{|c|}{0.001} & \multicolumn{2}{|c|}{0.000} & \multicolumn{2}{|c|}{0.000} & \multicolumn{2}{|c|}{0.000} & \multicolumn{2}{|c|}{0.000} \\
\hline \multicolumn{2}{|c|}{0.706} & \multicolumn{2}{|c|}{0.000} & \multicolumn{2}{|c|}{0.288} & \multicolumn{2}{|c|}{0.036} & \multicolumn{2}{|c|}{0.465} & \multicolumn{2}{|c|}{0.452} \\
\hline \multicolumn{2}{|c|}{0.987} & \multicolumn{2}{|c|}{0.295} & \multicolumn{2}{|c|}{0.161} & \multicolumn{2}{|c|}{0.907} & \multicolumn{2}{|c|}{0.433} & \multicolumn{2}{|c|}{0.089} \\
\hline
\end{tabular}


$(\mathrm{r}=-0.12)$, slow-wave sleep $(\mathrm{r}=-0.19)$, or other polysomnographic variables. Neither did the subjective ratings of "sleep quality", "ease of falling asleep", "calmness of sleep", or "sleep throughout the allotted time" show any significant correlation with naps $(r<0.20)$.

There was a significant effect of group with more symptoms of ache or tension and poorer levels of energy and physical activity in the burnout group than in the control group both for weekdays and the weekend. There was a different pattern for mood with less distress in both groups during the weekend. No significant interaction effect was found.

\section{Diurnal pattern of sleepiness and mental fatigue}

The mean levels of the diary ratings of sleepiness (KSS) and mental fatigue were calculated for each point in time for the workdays (Monday-Friday) and the weekend (Saturday-Sunday) (figure 1). There was a significant main effect for sleepiness with respect to group $(\mathrm{G})(\mathrm{F}$ $\left.{ }_{1,22}=20, \mathrm{P}=0.000\right)$, day (D) $\left(\mathrm{F}_{1,22}=17, \mathrm{P}=0.000\right)$, and time of day (ToD) $\left(\mathrm{F}_{4,88}=54, \mathrm{P}=0.000\right)$. The burnout group was sleepier than the controls, and there was a U-shaped diurnal pattern with a minimum during midday. Several interaction effects were found: $G \times D\left(F_{4,88}=7.2\right.$,
$\mathrm{P}=0.013), \mathrm{G} \times \mathrm{ToD}\left(\mathrm{F}_{4,88}=2.8, \mathrm{P}=0.032\right)$, and $\mathrm{D} \times \mathrm{ToD}$ $\left(\mathrm{F}_{4,88}=4.4, \mathrm{P}=0.007\right)$. Thus the difference between the groups was larger during the weekend, and the diurnal pattern was shallower in the burnout group. The diurnal pattern also differed between days so that the morning fall and evening rise of sleepiness was smaller and larger, respectively, during the weekend. The t-tests showed higher sleepiness for the burnout groups than for the control group for each point in time, both weekdays and weekends, except for the workweek afternoon when the controls were as sleepy as the burnout group (figure 1).

Repeated-measures ANOVA were also carried out to compare sleepiness levels on the different days within each group. No main effects of day were found for the burnout group, but a significant effect of time of day $\left(\mathrm{F}_{4,44}=31, \mathrm{P}=0.000\right)$ and of interaction (D x ToD, $\left.\mathrm{F}_{4,44}=3.0, \mathrm{P}=0.041\right)$ was found. For the controls, a significant effect of day $\left(\mathrm{F}_{1,11}=17, \mathrm{P}=0.002\right)$ and time of day $\left(F_{4,44}=42\right.$. $\left.P=0.000\right)$ was found, but there was no interaction. Thus the burnout group was as sleepy on weekends as on weekdays, and the diurnal pattern varied across the day with the lowest levels at midday. The sleepiness levels were higher at awakening during weekdays than on weekends $(t=2.7, P=0.021)$, however. The
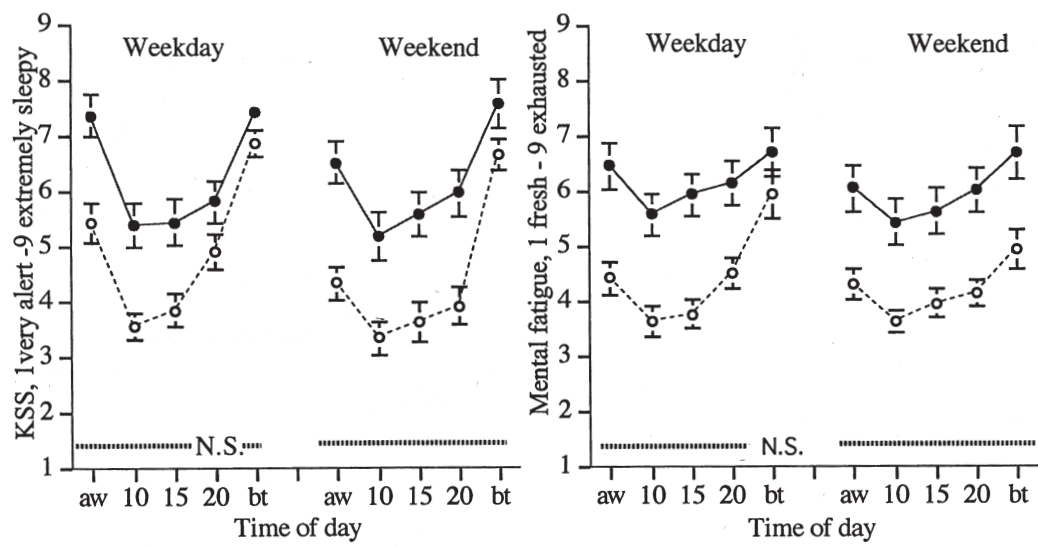

Figure 1. Diurnal variation (aw=awakening to bt =bedtime), mean and standard error of the mean of sleepiness on the Karlonska Sleepiness Scale, and mental fatigue in the burnout group (•) and healthy controls (०) during weekdays and weekend. Significant variations between groups are indicated by dotted lines above the abscissa. (N.S.=nonsignificant)

Table 4. Questionnaire data for the work characteristics, habitual sleep, rest burnout, and mood [results from the t-test, presented as the mean Questionnaire)

\begin{tabular}{|c|c|c|c|c|c|c|c|c|c|c|c|c|}
\hline \multirow[t]{3}{*}{ Group } & \multicolumn{8}{|c|}{ Work characteristics (ratings $1-4$ high or to a great extent) } & \multicolumn{4}{|c|}{ Habitual sleep } \\
\hline & \multicolumn{2}{|c|}{$\begin{array}{l}\text { Demands } \\
\text { at work }\end{array}$} & \multicolumn{2}{|c|}{$\begin{array}{l}\text { Decision } \\
\text { latitude }\end{array}$} & \multicolumn{2}{|c|}{$\begin{array}{c}\text { Time } \\
\text { pressure }\end{array}$} & \multicolumn{2}{|c|}{$\begin{array}{l}\text { Interference } \\
\text { with leisure } \\
\text { time }\end{array}$} & \multicolumn{2}{|c|}{$\begin{array}{l}\text { Habitual } \\
\text { sleep need } \\
\text { (hours:min) }\end{array}$} & \multicolumn{2}{|c|}{$\begin{array}{l}\text { Sleep deficit; } \\
\text { total sleep time } \\
\text { sleep need (min) }\end{array}$} \\
\hline & Mean & SE & Mean & SE & Mean & SE & Mean & SE & Mean & SE & Mean & SE \\
\hline Burnout $(\mathrm{N}=12)$ & 3.3 & 0.1 & 2.5 & 0.2 & 3.8 & 0.1 & 3.3 & 0.3 & $8: 25$ & $0: 13$ & -18 & $0: 20$ \\
\hline Control $(\mathrm{N}=12)$ & 2.4 & 0.3 & 3.2 & 0.2 & 2.8 & 0.2 & 1.9 & 0.3 & $7: 30$ & $0: 10$ & -7 & 0.10 \\
\hline $\mathrm{t}$-values ${ }^{a}$ & \multicolumn{2}{|c|}{2.2} & \multicolumn{2}{|c|}{-2.4} & \multicolumn{2}{|c|}{3.7} & \multicolumn{2}{|c|}{3.1} & \multicolumn{2}{|c|}{30.0} & \multicolumn{2}{|c|}{-0.5} \\
\hline P-values & \multicolumn{2}{|c|}{0.039} & \multicolumn{2}{|c|}{0.029} & \multicolumn{2}{|c|}{0.002} & \multicolumn{2}{|c|}{0.007} & \multicolumn{2}{|c|}{0.007} & \multicolumn{2}{|c|}{0.624} \\
\hline
\end{tabular}

a Degree of freedom 20-22. 
healthy controls perceived more alertness during the days off than on the weekdays, especially at awakening $(\mathrm{t}=4.5, \mathrm{P}=0.001)$ and in the evening $(\mathrm{t}=3.3, \mathrm{P}=0.007)$.

The same analysis for mental fatigue showed a significant main effect for group $\left(\mathrm{F}_{1,22}=20, \mathrm{P}=0.000\right)$, days $\left(\mathrm{F}_{2,44}=5.0, \mathrm{P}=0.035\right)$ and a $\mathrm{U}$-shaped time of day pattern in both groups $\left(\mathrm{F}_{4,88}=17, \mathrm{P}=0.000\right)$. The results indicated higher levels of mental fatigue among the burnout patients than among the controls and higher levels in the mornings and evenings, especially in the control group. No interactions were found. T-tests showed higher levels of mental fatigue for the burnout group at virtually all points in time (except for bedtimes during the workweek).

Repeated-measures ANOVA were also carried out to obtain an understanding of how mental fatigue varied between days within each group. No significant effects were found for the burnout group (BO) or the controls (C), except for the time of day (BO: $\mathrm{F}_{1,44}=4.3$, $\left.\mathrm{P}=0.007 ; \mathrm{C}: \mathrm{F}_{1,44}=17, \mathrm{P}=0.000\right)$, suggesting a consistent mental fatigue pattern across the weekdays.

\section{Questionnaires}

The results from the subjective ratings of the habitual sleep pattern, mood, and work characteristics in the questionnaire are presented in table 4 . For obvious reasons, the mean values for both of the burnout inventories were significantly higher for the patients than for the controls. The patients showed lower sleep quality and a greater need for sleep. No sleep deficit was found, however. None of the controls reached the criterion for insomnia according to DSM IV (14). Among the burnout patients, seven $(58 \%)$ met the criteria for insomnia according to the diagnostic criteria. The remaining five either did not report complaints of sleep $(\mathrm{N}=2)$ or complained solely of daytime fatigue $(\mathrm{N}=3)$. Even though the patients with ongoing major depression were excluded at the psychiatric screening, 58\% (7 persons) exceeded the clinical limit $(\geq 22)$ for depression on the BDI (range 10 to 37 ) (44), while 17\% (2 persons) scored above the same limit for anxiety $(\geq 22)$ on the BAI (range 5-27). There was an overlap of three persons for insomia and depression, and the two persons scoring above 22 on the BAI scored high on the BDI as well.

The work situation for the burnout patients 3 months before their sick leave was characterized by higher work demands, lower decision latitude, more time pressure, and work interference with leisure time. The burnout group did not differ from the control group in their time available to rest and recover, but they showed less ability to relax and unwind when they needed to.

\section{Discussion}

The main findings with regard to sleep were more arousals and fragmentation, more wake time and stage-1 sleep, lower sleep efficiency, less slow-wave and rapid eye movement sleep, a lower delta power density in nonrapid eye movement sleep, and lower subjective sleep quality in the burnout group. Considering the modest group sizes, the number of significant differences gives an impression of robust impairment.

The only similar work to compare the results with is our previous study of young workers with high burnout scores for whom we found an increased number of arousals (24). That relatively modest sleep disturbance was suggested to be a possible early sign of burnout, related to elevated psychological arousal due to acute stress or impaired recovery. Beyond the increased frequency of arousals, the present group showed a stronger sleep fragmentation in terms of awakenings, as well as more stage-1 sleep and wake time after sleep onset, suggesting a greater impairment of sleep. One reason may be more severe burnout symptoms in the present group (SMBQ $=5.8$ versus 4.8 in the previous study). Obviously, differences in age and the fact that the present group was not working may have played a role,

and standard error of the mean (SE)]. (BDI = Beck Depression Inventory, BAI = Beck Anxiety Inventory, SMBQ =Shirom Mekamed Burnout

\begin{tabular}{|c|c|c|c|c|c|c|c|c|c|c|c|}
\hline & & \multicolumn{4}{|c|}{ Recovery (ratings $1-5$ totally agree) } & \multicolumn{6}{|c|}{ Mood and burnout } \\
\hline \multicolumn{2}{|c|}{$\begin{array}{l}\text { Sleep quality } \\
\text { index } \\
(1-6=\text { good })\end{array}$} & \multicolumn{2}{|c|}{$\begin{array}{l}\text { I have enough } \\
\text { time available for } \\
\text { rest and recovery }\end{array}$} & \multicolumn{2}{|c|}{$\begin{array}{l}\text { I am able to } \\
\text { relax when } \\
\text { I need to }\end{array}$} & \multicolumn{2}{|c|}{$\begin{array}{l}\text { Depression, } \\
\text { BDI } \\
\text { (total score) }\end{array}$} & \multicolumn{2}{|c|}{$\begin{array}{c}\text { Anxiety, } \\
\text { BAl } \\
\text { (total score) }\end{array}$} & \multicolumn{2}{|c|}{$\begin{array}{c}\text { Burnout, } \\
\text { SMBQ } \\
\text { (1-7=high) }\end{array}$} \\
\hline Mean & SE & Mean & SE & Mean & SE & Mean & SE & Mean & SE & Mean & SE \\
\hline 3.1 & 0.2 & 3.5 & 0.3 & 2.3 & 0.3 & 22 & 3 & 14 & 2 & 5.6 & 0.4 \\
\hline 5.0 & 0.1 & 3.6 & 0.4 & 3.8 & 0.3 & 2.1 & 0.5 & 2.4 & 0.5 & 1.8 & 0.2 \\
\hline \multicolumn{2}{|c|}{-7.3} & \multicolumn{2}{|c|}{0.1} & \multicolumn{2}{|c|}{16.6} & \multicolumn{2}{|c|}{7.7} & \multicolumn{2}{|c|}{6.1} & \multicolumn{2}{|c|}{8.7} \\
\hline \multicolumn{2}{|c|}{0.000} & \multicolumn{2}{|c|}{0.708} & \multicolumn{2}{|c|}{0.001} & \multicolumn{2}{|c|}{0.000} & \multicolumn{2}{|c|}{0.000} & \multicolumn{2}{|c|}{0.000} \\
\hline
\end{tabular}


but sleep was severely impaired with respect to the most essential variables when the group was compared with healthy controls (of the same age). This difference remained also when daytime napping was controlled. Vital exhaustion is another concept representing extreme fatigue (45), and, in the only polysomnographic study available on vital exhaustion, slow-wave sleep was reduced similarly to that in the present study (46). Patients with chronic fatigue syndrome were excluded from our present study, but it appears that such patients exhibit reduced sleep efficiency but tend to extend their sleep (47). Furthermore, the level of sleep impairment in the present study is comparable with that found in moderate insomnia (48-50).

The mean level of diurnal sleepiness was considerably higher in the burnout group than in the control group. It was also considerably higher than in the study of young burnout workers (24). Again, one has to consider the differences in age, but, in contrast to what was the case in the previous study, the participants of our present study never reached the alert levels (3-4) during the day that the control group did. Incidentally, the level of sleepiness in the burnout group is similar to what has been found for shift workers during a night shift or during a morning shift with early rising $(51,52)$, and it must be considered to be far above normal levels. Thus, apart from the lack of recuperation during the weekend, which was seen also in our previous study (24), the drop in sleepiness during weekdays, as found in the other study, was lacking. The fact that the burnout group in the present study was on sick leave may have played a role, since the work-activity level may have had a masking effect on sleepiness. But since sleepiness is highly related to disturbed sleep $(53,54)$, and sleep was highly disturbed in this group, a possible conclusion is that the pattern of increased sleepiness during the day and across weekdays may be a characteristic of burnout in a more advanced stage.

As expected from the central role of fatigue in burnout, mental fatigue showed a diurnal pattern similar to that of sleepiness-with higher levels in the burnout group, but with a less pronounced time-of-day effect in both groups. While sleepiness is a well-established metric indicating a drive towards sleep (55), that of fatigue has received less attention as an acute estimate, and there are no available data to compare it with. The burnout group was on sick leave at the time of the study, and it is likely that the consistent pattern of mental fatigue across days may at least partly be explained by a disinclination towards activity (table 3 ). However, emotional and physical fatigue is closely intertwined (56), and physical symptoms of ache and muscle tension, as well as the high levels of distress and decreased energy in the present burnout group, may contribute to the experience of fatigue as well. The steady pattern of mental fatigue, independent of days, may also reflect co-morbidity with depression, this finding being supported by the high BDI scores (albeit the exclusion of severe cases), suggesting a more advanced phase of burnout. Even though the different dimensions of fatigue were not extensively explored in this study, mental fatigue seems to be an important variable in research on burnout and similar states and may provide information beyond that of sleepiness (25).

The disturbed sleep in the burnout group is a problem in its own right. However, it poses the interesting question of whether the impairment can contribute to the characteristic fatigue and sleepiness in burnout. The cross-sectional nature of our study does not permit any conclusions to be drawn in this regard. However, it may be of significance that sleep in the burnout group showed a duration of only 6 hours and 12 minutes. In light of recent observations that 7 hours of sleep as a level below which fatigue and sleepiness starts to accumulate $(23,57)$, it seems a distinct possibility that people with burnout get insufficient amounts of sleep. In addition, the fragmentation and higher level of stage-1 sleep suggests impaired recovery from sleep that may, in the long run, contribute further to the accumulation of fatigue independent of sleep length $(58,59)$. Even if compensation occurs during the weekend, the burnout group, in contrast to the controls, never reached their estimated levels of sleep need, and the amount reported in the diary was 39 minutes less than what the control group reported. It thus appears that further research into the role of sleep loss in burnout is warranted.

Work demands and persistent strain were clearly pronounced in the burnout group, reflecting the key role of stress in the development of burnout $(5,60)$. The higher level of "work interference with leisure" and "impaired ability to relax when needed" even "though time available is enough" probably reflects a state of being wound up and lack of recovery, and the psychiatric interview clearly indicated that stress preceded burnout. Even if the observations on stress causing burnout are convincing, they are still retrospective. Strictly speaking, no prospective studies on stress precipitating burnout seem to exist (as is the case also with insomnia) (61). There seems to be good reasons for suspecting that insomnia precipitates depression, however (62).

While not the focus of our study, it is an interesting observation that sleep loss may cause high physiological arousal and increased activity in, for example, the hypothalmo-pituitary-adrenal (HPA) axis (63) and that increased HPA-axis activation may exacerbate sleep disturbances $(64,65)$. In addition, proinflammatory cytokines are potent stimulants of the HPA axis (66), and, for example, tumor necrosis factor-alpha and interleukin-6 are associated with somnolence and fatigue (67, 68), whereas experimentally reduced sleep increases 
levels of proinflammatory cytokines $(69,70)$. Thus immunoneuroendocrine alterations could play a role in the pathophysiology of the disturbed sleep and excessive fatigue in burnout. This possibility remains to be demonstrated, however.

It should be emphasized that the naturalistic design of our study, while necessary for the present purpose, may involve confounding by co-morbidity. While people with several types of co-morbidity were excluded after psychiatric screening, those with moderate symptoms of depression were retained because of the ubiquitous presence of such symptoms in burnout $(14,15$, 71). The overlap with depression is in line with what is found in other studies on burnout $(72,73)$ and should be viewed against the fact that depression scales load rather heavily on fatigue. However, the BDI scores were tested as covariates in our analysis, and there was no relation between depression and sleep parameters. This finding suggests a lack of influence of depression on the sleep parameters, but further research into the role of depression in burnout is warranted.

Furthermore, the present group did not use any medication, whereas selective serotonin re-uptake inhibitors are commonly prescribed for burnout patients. Since one might hypothesize a correlation between the severity of the state and pharmacological intervention, it is possible that the difference from the controls may be larger in a medicated group.

In summary, the present study has shown that burnout patients are characterized by severely disturbed sleep and high levels of sleepiness and fatigue that do not dissipate during the weekend. Whether sleep impairment is involved in the development of burnout (excessive fatigue) should be addressed in longitudinal studies, as should the role of depression.

\section{Acknowledgments}

This study was supported by the Alecta Insurance Company, the Swedish Working Life Institute, and the Swedish Research Council for Working Life and Social Sciences.

We would like to thank all the participants for their collaboration.

\section{References}

1. Weber A, Jaekel-Reinhard A. Bournout syndrome: a disease of modern societies? Occup Med. 2000;50:512-7.

2. Riksförsäkringsverket (RFV). Långtidssjukskrivna—egenskaper vid 2003 års RFV-LS-undersökning: redovisning [Long term sick leave-characteristics of 2003 RFV-LS investiga- tion: results presentation]. Stockholm: Riksförsäkringsverket [National Board of Social Insurances]. Report no 4.

3. Shirom A. Burnout in work organizations. In: Cooper CL, Robertson I, editors. International review of industrial and organizational psychology. New York (NY): John Wiley \& Sons Ltd; 1989. p. 25-48.

4. Freudenberger HJ. Staff burn-out. J Soc Issues. 1974;30:159_ 65 .

5. Maslach C, Jackson S. The measurement of experienced burnout. J Occup Behav. 1981;2:99-113.

6. Maslach C, Jackson SE, Leiter MP. Maslach burnout inventory manual. Third ed. Palo Alto (CA): Consulting Psychologists Press, Inc; 1996.

7. Kalimo R. Knowledge jobs-how to manage without burnout? Scand J Work Environ Health. 1999;25 special issue:6059.

8. Melamed S, Kushnir T, Shirom A. Burnout and risk factors for cardiovascular diseases. Behav Med. 1992;18:53-60.

9. Kushnir T, Melamed S. The Gulf War and its impact on burnout and well-being of working civilians. Psychol Med. 1992;22:987-95.

10. World Health Organization (WHO). International statistical classification of diseases and related health problems. Geneva: WHO; 1992.

11. Socialstyrelsen [The National Board of Health and Welfare]. Ändringar i och tillägg till klassifikation av sjukdomar och hälsoproblem 1997 (KSH97)—systematisk förteckning [Supplement to classification of diseases 1997 (KSH97)systematic list.]. Stockholm: Socialstyrelsen; 2005. [Cited 2005 jan 1]. Available from: http://www.sos.se/epc/klassifi/ KSHandr.htm\#Andr2005.

12. Demitrack MA, Abbey SE. Historical overview and evolution of contemporary definitions of chronic fatigue states. New York (NY): The Guilford Press; 1996.

13. Appels A, de Vos Y, van Diest R, Höppner P, Mulder P, de Groen J. Are sleep complaints predictive of future myocardial infarction? Act Nerv Super (Praha). 1987;29:147-51.

14. American Psychiatric Association (APA). The diagnostic and statistical manual of mental disorders (DSM-IV-TR). 4th ed. Arlington (VA): APA; 1994. 22209-3901.

15. Leiter MP, Durup J. The discriminant validity of burnout and depression: a confirmatory factor analytic study. Anxiety Stress Coping. 1994;7:357-373.

16. Åhsberg E, Gamberale F, Kjellberg A. Perceived quality of fatigue during different occupational tasks development of a questionnaire. Int J Ind Ergon. 1997;20:121-35.

17. Åhsberg E, Kecklund G, Åkerstedt T, Gamberale F. Shiftwork and different dimensions of fatigue. Int J Ind Ergon. 2000;26:457-65.

18. Rosmond R, Björntorp P. Låg kortisolproduktion vid kronisk stress [Low cortisol production in chronic stress]. Läkartidningen 2000;97:4120-4

19. McEwen BS, Seeman T. Protective and damaging effects of mediators of stress. Ann N Y Acad Sci. 1999;896:30-47.

20. Melamed S, Ugarten U, Shirom A, Kahana L, Lerman Y, Froom P. Chronic burnout, somatic arousal and elevated salivary cortisol levels. J Psychosom Res. 1999;46:591-8.

21. Grossi G, Perski A, Evengård B, Blomkvist V, Orth-Gomér K. Physiological correlates of burnout among women. J Psychosom Res. 2003;55:309-16.

22. Bonnet MH. Sleep deprivation. In: Kryger M, Roth T, Dement W, editors. Principles and practice of sleep medicine. Philadelphia (PA): WB Saunders Company; 1994. p. 50-67.

23. Van Dongen HP, Maislin G, Mullington JM, Dinges DF. The 
cumulative cost of additional wakefulness: dose-response effects on neurobehavioral functions and sleep physiology from chronic sleep restriction and total sleep deprivation. Sleep. 2003;26(2):117-26.

24. Söderström M, Ekstedt M, Åkerstedt T, Nilsson J, Axelsson J. Sleep and sleepiness in young individuals with high burnout scores. Sleep. 2004;17:1369-77.

25. Dement WC, Hall J, Walsh JK. Tiredness versus sleepiness: semantics or a target for public education? Sleep. 2003;26(4):485-6.

26. Perski A, Grossi G, Evengård B, Blomkvist V, Ylbar B, OrthGomér K. Emotional exhaustion common among women in the public sector. Läkartidningen. 2002;99:2047-52.

27. First MB, Gibbon M, Spitzer RL, Williams JBW. Structured clinical interview for DSM-IV axis I disorders (SCID-I), clinical version. Washington (DC): American Psychiatric Press, Inc; 1997.

28. Deykin EY, Keane TM, Kaloupek D, Fincke G, Rothendler J, Siegfried M, et al. Posttraumatic stress disorder and the use of health services. Psychosom Med. 2001;63(5):835-41.

29. First MB, Gibbon M, Spitzer RL, Williams JBW, Smith Benjamin L. Structured clinical interview for DSM-IV axis II personality disorders (SCID-II). Washington (DC): American Psychiatric Press, Inc; 1997.

30. Rechtschaffen A, Kales A. A manual of standardized terminology, techniques and scoring system for sleep stages of human subjects. Bethesda (MA): US Department of Health, Education and Welfare, Public Health Service; 1968.

31. American Sleep Disorders Association (ASDA). EEG arousals: scoring rules and examples. Sleep. 1992;15:173-84.

32. Pines AM, Aronson E, Kafry D. The research. In: Burnout from tedium to personal growth. New York (NY): The Free Press; 1981. p. 202-5.

33. Beck AT, Ward CH, Mendelson M, Mock J, Erbaugh J. An inventory for measuring depression. Arch Gen Psychiatry. 1961;4:561-71.

34. Beck AT, Epstein N, Brown G, Steer RA. An inventory for measuring clinical anxiety: Psychometric properties. J Consult Clin Psychol. 1988;56(6):893-7.

35. Åkerstedt T, Knutsson A, Westerholm P, Theorell T, Alfredsson L, Kecklund G. Sleep disturbances, work stress and work hours: a cross-sectional study. J Psychosom Res. 2002;53:7418 .

36. Karasek RA. Job demands, job decision latitude and mental strain. Implications for job redesign. Adm Sci Q. 1979;24:285-308.

37. Siegrist J. Adverse health effects of high-effort/low-reward conditions. J Occup Health Psychol. 1996;1:27-41.

38. Lowden A, Åkerstedt T. Jet lag in air crew-a questionnaire study. Stress Res Rep. 1993;237:1-20.

39. Åkerstedt T, Hume K, Minors D, Waterhouse J. The subjective meaning of good sleep, an intraindividual approach using the Karolinska Sleep Diary. Percept Mot Skills. 1994;79:287296.

40. Åkerstedt T, Hume K, Minors D, Waterhouse J. The meaning of good sleep: a longitudinal study of polysomnography and subjective sleep quality. J Sleep Res. 1994;3:152-158.

41. Kecklund G, Åkerstedt T. Objective components of individual differences in subjective sleep quality. J Sleep Res. 1997;6:217-220.

42. Åkerstedt T, Gillberg M. Subjective and objective sleepiness in the active individual. Int J Neurosci. 1990;52:29-37.

43. Huynh H, Feldt LS. Estimation at the box correction for degrees of freedom for sample data in randomised block and split-plot designs. J Educ Stat. 1976;1:69-82.

44. Lasa L, Ayuso-Mateos JL, Vázquez-Barquero JL, Diez-Manrique FJ, Dowrick CF. The use of the Beck depression inventory to screen for depression in the general population: a preliminary analysis. J Affect Disord. 2002;57:261-65.

45. Appels A, Falger PRJ, Schouten EGW. Vital exhaustion as risk indicator for myocardial infarction in women. J Psychosom Res. 1993;37:881-90.

46. van Diest R, Appels AWPM. Sleep physiological characteristics of exhausted men. Psychosom Med. 1994;56:28-35.

47. Sharpley A, Clements A, Hawton K, Sharpe M. Do patients with "pure" chronic fatigue syndrome (Neurasthenia) have abnormal sleep? Psychosom Med. 1997;59:592-6.

48. Bonnet MH, Arand DL. Situational insomnia: consistency, predictors, and outcomes. Sleep. 2003;26(8):1029-36.

49. Morin CM, Stone J, Trinkle D, Mercer J, Remsberg S. Dysfunctional beliefs and attitudes about sleep among older adults with and without insomnia complaints. Psychol Aging. 1993;8:463-467.

50. American Association of Sleep Medicine (AASM). American Association of Sleep Medicine international classification of sleep disorders-diagnostic and coding manual. Chicago (IL): AASM; 2001.

51. Kecklund G, Åkerstedt T, Lowden A. Morning work: Effects of early rising on sleep and alertness. Sleep. 1997;20(3):21523.

52. Ingre M, Kecklund G, Åkerstedt T, Kecklund L. Variation in sleepiness during early morning shifts: a mixed model approach to an experimental field study of train drivers. Chronobiol Int. 2004;21:973-90.

53. Bonnet MH. Performance and sleepiness following moderate sleep disruption and slow wave sleep deprivation. Physiol Behav. 1986(37):915-8.

54. Bonnet MH, Arand DL. Clinical effects of sleep fragmentation versus sleep deprivation. Sleep Med Rev. 2003;7(4):297310 .

55. Dement WC, Carskadon MA. Current perspectives on daytime sleepiness: the issues. Sleep. 1982;5:56-66.

56. Cameron C. A theory of fatigue. Ergonomics. 1973;16:63348.

57. Belenky G, Wesensten NJ, Thorne DR, Thomas ML, Sing HC, Redmond DP, et al. Patterns of performance degradation and restoration during sleep restriction and subsequent recovery: a sleep dose-response study. J Sleep Res. 2003;12(1):112.

58. Gillberg M. Sleepiness and its relation to the length, content, and continuity of sleep. J Sleep Res. 1995;4 suppl 2:37-40.

59. Bonnet MH, Arand DL. Impact of activity and arousal upon spectral EEG parameters. Physiol Behav. 2001;74:291-8.

60. Freudenberger HJ. Burnout: Contemporary issues, trends, and concerns. In: Farber BA, editor. Stress and burnout. New York (NY): Anchor Press/Doubleday; 1983. p. 23-8.

61. Morin CM, Rodrigue S, Ivers H. Role of stress, arousal, and coping skills in primary insomnia. Psychosom Med. 2003;65:259-67.

62. Ohayon MM, Roth T. Place of chronic insomnia in the course of depressive and anxiety disorders. J Psychiatr Res. 2003;37:9-15.

63. Vgontzas AN, Bixler EO, Lin H-M, Prolo P, Mastorakos G, Vela-Bueno A, et al. Chronic insomnia is associated with nyctohemeral activation of the hypothalamic-pituitary-adrenal axis: clinical implication. J Clin Endocrinol Met. 2001;86:3787-94.

64. Chrousos GA, Kattah JC, Beck RW, Cleary PA. Side effects 
of glucocorticoid treatment: experience of the optic neuritis treatment trial. JAMA. 1993;269(16):2110-2.

65. Vgontzas AN, Chrousos GP. Sleep, the hypothalamic-pituitary-adrenal axis, and cytokines: multiple interactions and disturbances in sleep disorders. Endocrinol Metab Clin North Am. 2002;31:15-36.

66. Buckley TM, Schatzberg AF. On the Interactions of the HPA axis and sleep: normal HPA axis and rhythm, exemplary sleep disorders. J Clin Endocrinol Metab. 2005;13(5):344-52.

67. Vgontzas AN, Papanicolaou DA, Bixler EO, Kales A, Tyson $\mathrm{K}$, Chrousos GP. Elevation of plasma cytokines in disorders of excessive daytime sleepiness: role of sleep disturbance and obesity. J Clin Endocrinol Metab. 1997;82(5):1313-6.

68. Papanicolaou DA, Amsterdam JD, Levine S, McCann SM, Moore RC, Newbrand CH, et al. Neuroendocrine aspects of chronic fatigue syndrome. Neuroimmunomodulation. 2004;11(2):65-74.

69. Moldofsky H, Lue F, Eisen J, Keystone E, Gorczynski R. The relationship of interleukin-1 and immune functions to sleep in humans. Psychosom Med. 1986;48:309-18.

70. Vgontzas AN, Zoumakis M, Bixler EO, Lin H-M, Prolo P, Vela-Bueno A, et al. Impaired nighttime sleep in healthy old versus young adults is associated with elevated plasma interleukin-6 and cortisol levels: physiologic and therapeutic implications. J Clin Endocrinol Metab. 2003;88:2087-95.

71. De Vente W, Olff M, Van Amsterdam JGC, Kamphuis JH, Emmelkamp PMG. Physiological differences between burnout patients and healthy controls: blood pressure, heart rate, and cortisol responses. Occup Environ Med. 2003;60:i54-i61.

72. Åsberg M, Nygren Å, Rylander G, Rydmark I. Stress och utmattningsdepression. In: Rolf Ekman BA, editor. Stress. Stockholm: Liber; 2002. p. 224-32.

73. Hallsten L. Burning out: a framework. In: Schaufeli W, Maslach C, Marek T, editors. Professional burnout: recent developments in theory and research. Washington (DC): Taylor \& Francis; 1993. p. 95-113.

Received for publication: 27 March 2005 